\title{
Research on the Strategic Transformation of Vertical B2C E-commerce Industry
}

\author{
Feng Xiaolan ${ }^{1, a}$ \\ ${ }^{1}$ Xi'an Fanyi University,Shaanxi xi 'an, 710105 \\ ${ }^{\text {a }}$ email
}

Keywords: Strategic Transformation, Vertical B2C E-commerce, Economic Development

\begin{abstract}
With the continuous development of social economy, e-commerce model, in the increasingly fierce competition in the market environment has gradually been developed and innovative, from the past, the traditional business model evolved into the current vertical e-commerce model. In the vertical e-commerce, the most representative model is the $\mathrm{B} 2 \mathrm{C}$ e-commerce model. We know that e-commerce economic model in China has about 16 years of development process, of course, vertical B2C e-commerce model started late, but its rapid development speed, which is due to its own characteristics and advantages. This article takes a vertical B2C e-commerce network marketing model as the research object, its in-depth discussion.
\end{abstract}

\section{Introduction}

Vertical B2C e-commerce network marketing platform performance in two aspects: Professional, specific. It refers to focus on all the resources and strength to build a professional network of goods sales information platform, mainly for their own industry for the development of a particular focus on a class of goods industry to do a comprehensive study, such as shoes, clothes, electrical appliances. This major development direction is also one of its main features, with a very unique professional nature. It is in the professional sales on the basis of further research. Because the professional, specifically the vertical site to do the prerequisite for the development of the deep and further development is to be able to improve the quality of service products and improve business profits. In the vertical B2C e-commerce network marketing model under the influence of many companies and websites have started with some well-known brands of manufacturers to communicate and cooperation, not only can resolve the interests of the channel business conflict, but also continue to expand the product line and Product line, in order to better improve the trading platform for pre-sale, sale, after-sales service, and provide a more diversified way of payment of commodity transactions.

\section{Development and Application of Vertical B2C E - commerce}

This narrowness is relatively speaking, because the vertical B2C network marketing platform itself is facing a relatively single product market. For example, the main clothing apparel products and services, so its consumer groups also have a relatively simple, popular point that consumers are for this type of product to your website for shopping. Because of this, now more and more by the impact of integrated B2C business model and the threat, but because there is a good side, so the majority of consumer groups and consumer motivation in the choice of the above is still very wise, this good side is the stability mentioned. Stability in the stability of the consumer groups, the stability of the market, vertical B2C business enterprises in the maintenance of consumer relations and management has stability, while vertical B2C network marketing process of commodity prices compared with certain the price advantage. It can provide consumers with better quality more professional products and services, will inevitably accumulate a large consumer groups, although the network marketing process will be a lot of loss of some customers, but rely on the vertical B2C platform's own advantages and characteristics, improve sales And the quality of service, continue to meet the needs of consumers, will strive for more market share. However, many of the current vertical enterprises in this area is not very good, need to improve and innovation. 
This is also due to the current status of Chinese logistics decision, although the development of Chinese logistics industry is very fast, the scale is constantly expanding, but because the start time is relatively late, so many logistics industry market mechanism is not perfect. Especially in the context of the rapid development of Internet e-commerce model, the lack of efficient modern logistics management technology and logistics system, it also directly affects the vertical B2C logistics process. Because of the traditional e-commerce model, they have a common feature, that is, logistics and distribution. Logistics and distribution is vertical B2C e-commerce network marketing process is an extremely important part of Chinese logistics system is not sound enough, the logistics speed is often very slow, it may lead to customer goods in the transport process caused damage. For example, when the Golden Week, online shopping transactions increased significantly, resulting in many of the electricity companies logistics companies appear explosive situation, it will cause the delivery of goods is very slow, a serious impact on consumer sentiment And shopping mood, and finally become the constraints of vertical B2C e-commerce network marketing model development of the important negative factors.

Whether it is the traditional e-commerce model or modern e-commerce model, the network marketing the biggest features and advantages is low cost. In other words, vertical B2C businesses and businesses can not be limited by space time and place, as long as they have enough goods and goods, can be placed on the B2C network marketing platform for customers to choose. As we are most familiar with the world's largest merchandise retailer Wal-Mart, it is quite cost advantage, but in the vertical B2C network marketing platform, the cost of the price is far lower than the real life of Wal-Mart. With the Internet customers on the vertical B2C business enterprise traffic surge, then the marginal cost of the enterprise will show a downward trend, so that the enterprise's profit margins to maximize.

Chinese current vertical B2C e-commerce network marketing model lacks the corresponding technology and management system innovation, basically still remain in some foreign advanced e-commerce business management model imitation level, many domestic e-commerce model, Most of them are foreign advanced business model of transplantation. EBay's business model is basically imitating foreign eBay, like Dangdang is also a foreign advanced business management model for the transplant.

\section{Vertical B2C E-Commerce Marketing Model and Its Strategy}

We have to say that the network marketing is to promote Chinese e-commerce process is the most important and most direct force in the context of the development of the network environment, vertical B2C e-commerce for the traditional e-commerce network marketing model improvements, and through Targeted reform and development has been very good development, this marketing model and marketing strategy changes are mainly reflected in the following important aspects, the following one to elaborate.

Clear the target market positioning is the vertical B2C e-commerce marketing model of the most important principles of construction, vertical B2C e-commerce marketing model to establish the full combination of consumer demand, the implementation of precision marketing strategy, according to their own to operate the field Of the product characteristics of positioning, which is vertical B2C e-commerce marketing model to carry out the prerequisite for precision marketing market positioning can be carried out from the study of customer psychology. According to the customer's purpose and type of the Internet, the customer classified as browsing, work type, enjoy several categories, the full study of customer psychology, customer consumption concepts and consumer demand is also an important direction of precision marketing, and we also should be fully aware of the needs of customers is diversified, and actively use of modern information technology, combined with large data age to facilitate the analysis of potential customers, so with a certain advertising model and other common marketing methods to seize the target customers. The network marketing model in the market positioning, for example, network from the geographical and population factors will target their own customers, geographically will be the potential consumption of alcohol consumption groups are divided into two categories, namely Economically developed areas, coastal 
mega-cities and a second-tier cities, from the composition of the population to analyze their potential consumer groups are more familiar with e-commerce 80,90 after the crowd, mainly for income levels and high levels of consumption of young successful people, So as to help Jiuxian net firmly grasp the market trends, the construction of marketing model for the establishment of a market base.

Compared to the traditional e-commerce, on the cost and supply chain management, vertical B2C e-commerce more attention to the low price to capture the market, the main reason is that such sites have a specific product areas, so with the field of business There is a very close cooperation, such as Jiuxian network, Dangdang for the area of goods upstream manufacturers have more intimate cooperation, but relative to the cost and supply chain management, the low-cost strategy is in fact a certain risk, Especially in the event of capital vacancies, low-cost strategy simply do not have any ability to resist risk. So now the vertical B2C e-commerce more began to pay attention to and return to the conventional supply chain management, and gradually out of the low-cost strategy of marketing strategies and methods, more emphasis on strengthening the supply chain brand management and construction, more consumer affirmation, and then get rid of the dependence on price marketing. As the areas involved are relatively fixed and specific, so the supply chain management model is also the vertical B2C e-commerce the most core marketing links, and vertical B2C e-commerce business to improve the level of business an important way through the supply chain science Reasonable management, with the information technology for the consumption of such information in the sorting and data analysis, both to meet the specific needs of customers can also avoid inventory pressure, and in the process of continuous accumulation of valuable data information, with large data Time for the data link and analysis process, and gradually the information and data analysis applied to the daily supply chain management.

Warehousing and logistics infrastructure is an important basis for any e-commerce construction, and vertical B2C e-commerce in this area has also been a certain optimization, especially in order to meet the specific and precise positioning of consumers in the overall service strategy and system The construction process of continuous improvement and then meet customer needs. Through the construction of their own characteristics to meet the storage and logistics system, is the vertical B2C e-commerce network sales model based on the link, in order to improve the vertical B2C e-commerce brand influence, improve customers for vertical B2C e-commerce merchandise trust, Warehousing and logistics self-built vertical B2C e-commerce had to face the problem, warehousing and logistics self-built not only to expand the impact of specific type of brand, but also can greatly reduce the cost of operations. Most of our traditional e-commerce use third-party logistics to distribution, once encountered holidays and other major promotional activities often appear when the explosion situation and this is clearly perpendicular to the B2C e-commerce marketing model is contrary to, and very is not conducive to the maintenance of its customer loyalty and relationship.

With the continuous development of e-commerce, the combination of network and consumer life to further deepen, word of mouth marketing play an increasingly important role, and vertical B2C e-commerce to face a specific consumer demand for consumer groups, those People with specific consumer demand for purchase decisions are often based on the experience of consumers to buy on the evaluation, such as a person in the wine cents to buy a bottle of wine, and the purchase experience and experience to give a positive evaluation, Then it will greatly promote the consumer experience to hear the consumer experience and consumer desire to buy, word of mouth marketing is almost all the e-commerce marketing model is an important way, because the vertical B2C e-commerce sales model is the core of precision marketing, So it should pay more attention to the importance of word of mouth marketing, pay attention to product brand building, relying on word of mouth to improve the attractiveness of target customers to improve the specific consumer groups for such consumer goods in the vertical B2C e-commerce dependence, and thus improve their market Competitiveness. 


\section{Conclusion}

Service platform and user platform will become Chinese B2C e-commerce research focus. For large enterprises, how to play a good service platform to achieve the role of business model innovation, remains to be further explored. We should build a variety of platforms with great potential business value around the user, how to tap and use this value is also worthy of further study.

\section{References}

[1] Shao Bingjia, Gao Zhixin. B2C e-commerce website trust level and countermeasures [J]. Library and Information Work, 2010 (18)

[2] Yang Chao, Zhao Kun. B2C e-commerce development strategy and service model research [J]. Economics and Management, 2010 (08)

[3] Chen Na, Cao Fanghua. Jingdong Mall: vertical e-commerce victory [J]. Sales and marketing (comment version), 2010 (05)

[4] Zhang Jinglai, Meng Xianzhong. The local B2C e-commerce model innovation research [J]. Marketing Guide, 2009 (06)

[5] Liu Deliang. Network brand: B2C e-commerce magic [J]. Sales and marketing (management), 2009 (08)

[6] Yang Yunyong. Analysis of the economic characteristics of e-commerce and its impact on economic structure [J]. Shopping modernization, 2008 (32) 